\title{
A prescrição do crédito da Fazenda Pública e a execução fiscal
}

\author{
Eurípedes Gomes Paim Filho*
}

\section{PRESCRIÇÃO TRIBUTÁRIA}

A prescrição no Direito Civil é a perda da pretensão,' ou seja, da possibilidade de exigir um direito em juízo em decorrência da inatividade do titular na defesa do seu direito por certo lapso de tempo, de acordo com a máxima latina dormientibus non sucurrit jus.

Isso não significa a perda do direito de ação, que não se perde nunca, pois mesmo quando o crédito estiver prescrito e for intentada uma execução o direito de ação terá sido exercido pela propositura da execução, embora essa esteja fadada à extinção. ${ }^{2}$

Já no caso do Direito Tributário, com a prescrição ocorre a extinção do crédito tributário e não meramente da pretensão, conforme o art. 156, V, do Código Tributário Nacional.

Essa diferença entre o Direito Tributário e o Direito Civil tem importância, pois o pagamento de uma dívida civil prescrita é válido, já o pagamento de uma dívida tributária prescrita não o é,

\footnotetext{
* Juiz de Direito titular da Vara da Fazenda Pública de São Vicente, SP. Mestre em Direito pela USP. Professor de Direito. Sócio do IBDT-USP.

1 Código Civil de 2002: "Artigo 189. Violado o direito, nasce para o titular a pretensão, a qual se extingue, pela prescrição, nos prazos a que aludem os arts. 205 e 206. " (grifo nosso) 2 Contra entendendo ser perda do direito de ação: CASSONE, Vittorio; CASSONE, Maria Eugenia Teixeira. Processo tributário. 4. ed. São Paulo: Atlas, 2003, p. 42. ICHIHARA, Yoshiaki. Direito tributário. 9. ed. São Paulo: Atlas, 2000, p. 165. HARADA, Kiyoshi. Direito financeiro e tributário. 11. ed. São Paulo: Atlas, 2003, p. 464. Esse último autor menciona a idéia da perda da pretensão, no entanto opta por afirmar que há perda do direito de ação.
} 
cabendo nesse último caso repetição de indébito, ${ }^{3}$ sendo a prescrição tributária irrenunciável por ser matéria de ordem pública. ${ }^{4}$

A esse respeito convém lembrar as seguintes regras do Código Tributário Nacional:

Art. 109. Os princípios gerais de direito privado utilizam-se para pesquisa da definição, do conteúdo e do alcance de seus institutos, conceitos e formas, mas não para definição dos respectivos efeitos tributários.

Art. 110. A lei tributária não pode alterar a definição, o conteúdo e o alcance de institutos, conceitos e formas de direito privado, utilizados, expressa ou implicitamente, pela Constituição Federal, pelas Constituições dos Estados, ou pelas Leis Orgânicas do Distrito Federal ou dos Municípios, para definir ou limitar competências tributárias. (Grifo nosso).

Portanto, a lei tributária pode estabelecer efeitos tributários diversos dos institutos jurídicos de outras áreas, salvo se relacionados à distribuição ou limita- ção de competências tributárias. Assim, a prescrição, que na verdade é um princípio geral do Direito, não só do Direito Privado, pode receber um tratamento tributário próprio, o que ocorreu como mencionado neste texto. ${ }^{5}$

A prescrição tributária diverge da decadência tributária por ser essa a perda do direito de constituir o crédito tributário pelo lançamento, sendo que a prescrição só se inicia após findo o lançamento como passamos a ver.

\section{INÍCIO DO PRAZO DE PRESCRIÇÃO}

Constituido o crédito tributário, o que, na linguagem do Código Tributário Nacional, significa tornar o crédito exeqüível pela determinação de sua liquidação e certeza, começa a correr o prazo de prescrição. ${ }^{6}$

A constituição do crédito tributário ocorre com o lançamento, naqueles casos em que o ato da autoridade é imprescindível, ou seja, no denominado lançamento de oficio, o que é comum de ocorrer, por exemplo, no IPTU.

3 Contra, entendendo não caber repetição de indébito: ICHIHARA, op. cit., p. 170.

4 Contra, entendendo ser renunciável: HARADA, op. cit., p. 464.

5 Da mesma forma a lei penal dá à prescrição um tratamento diverso do dado pela lei civil dizendo que a prescrição extingue a punibilidade, ou seja, o direito material de punir do Estado, não apenas a pretensão ou o direito de ação: "Código Penal [...] Art. 107 Extingue-se a punibilidade: (Redação dada pela Lei $n^{\circ} 7.209$, de 11.7.1984) IV - pela prescrição, decadência ou perempção; [...]" (grifo nosso)

6 Contra, entendendo que é a partir da notificação: CAIS, Cleide Previtalli. O processo tributário. 4. ed. São Paulo: Revista dos Tribunais, 2004, p. 689. Contudo, mantemos a posição do texto, pois de acordo com a redação do art. 174 do Código Tributário Nacional. 
Há casos em que o lançamento se dá por um auto de infração, caso em que daí começa a correr o prazo prescricional.

Há situações nas quais o contribuinte deve recolher o tributo independente de atividade administrativa, o que o Código chama de lançamento por homologação e alguns indevidamente chamam de auto-lançamento, pois, a rigor, nesses casos não há verdadeiro lançamento, pois o fisco já tem o crédito liquidado e certo.

Também há casos de declaração de dívida feita pelo contribuinte, dependendo de uma averiguação pelo físco.

Nos dois últimos casos, se houver uma diferença em favor do fisco, o prazo será de decadência, pois, quanto a essa diferença, não houve lançamento e essa diferença deverá ser lançada de ofício, não tendo começado nessa situação o prazo de prescrição com relação à diferença ou mesmo quanto ao débito declarado e não pago, pois ainda pendente de averiguação feita pelo lançamento.

O lançamento só é mesmo definitivo quando insuscetível de recurso ou de revisão de ofício, de acordo com as leis de cada entidade tributante. A data da inscrição do crédito na dívida ativa não marca esse momento, pois o crédito tem que estar constituído antes da sua inscrição. ${ }^{?}$

\section{PRAZO, SUSPENSÃO E INTERRUPÇÃO DA PRESCRIÇÃO}

Dispõe o Código Tributário Nacional, no seu artigo 174 que "a ação para a cobrança do crédito tributário prescreve em cinco anos, contados da data da sua constituição definitiva." Esse prazo não se prorroga até o dia útil seguinte caso o último dia venha a cair em dia não útil, pois não há previsão nesse sentido na lei. ${ }^{8}$

O Código Tributário Nacional não trata especificamente da suspensão da prescrição, contudo prevê a suspensão da exigibilidade do crédito tributário nos seguintes casos:

Art. 151. Suspendem a exigibilidade do crédito tributário:

I- moratória;

II - o depósito do seu montante integral;

III - as reclamações e os recursos, nos termos das leis reguladoras do processo tributário administrativo;

$I V$ - a concessão de medida liminar em mandado de segurança;

7 Nesse sentido: COÊLHO, Sacha Calmon Navarro. Curso de direito tributário brasileiro. 6. ed. Rio de Janeiro: Forense, 2001, p. 723. COÊLHO, Sacha Calmon Navarro. Manual de direito tributário. 2. ed. Rio de Janeiro: Forense, 2003, p. 477. Contra, entendendo que a possibilidade de alteração não significa falta de definitividade e que o prazo se inicia com a expedição da certidão da dívida ativa: ICHIHARA, Direito..., p. 168 e p. 170.

8 Contra, entendendo haver prorrogação para o primeiro dia útil seguinte: (Ibidem, p. 170). 
$V$ - a concessão de medida liminar ou de tutela antecipada, em outras espécies de ação judicial: (Incluido pela Lcp $n^{\circ}$ 104, de 10.1.2001)

$V I-o$ parcelamento. (Incluido pela Lcp $n^{\circ}$ 104, de 10.1.2001)

Como se viu acima, diversamente do Direito Civil, no Direito Tributário a prescrição extingue não somente a pretensão, mas também o crédito, assim, não se pode dizer que a suspensão da exigibilidade, ou seja, da pretensão, seja causa de suspensão da prescrição tributária. ${ }^{9}$

Tanto é assim que o Código é taxativo ao prever a suspensão da prescrição apenas no art. 155, parágrafo único, ou seja, nas moratórias, e somente naquelas em que houver dolo ou simulação do beneficiado, ou de terceiro em benefício daquele, caso em que o tempo decorrido entre a concessão da moratória e sua revogação não se computa para efeito da prescrição do direito à cobrança do crédito.

O depósito do montante integral, que só faz. sentido se tiver o objeto de evitar os efeitos da mora durante uma discussão, pode ser feito na fase administrativa, quando o lançamento ainda não está terminado e, portanto, ainda não começou a correr a prescrição.

Especificamente no caso do inciso III do art. 151, o crédito ainda não foi definitivamente constituido pelo lançamento e, assim, a prescrição nem começou a correr.

As liminares e antecipações também podem ser concedidas ainda durante o processo administrativo do lançamento, razão pela qual não suspendem a prescrição que ainda não se iniciou.

Finalmente, o parcelamento, a hipótese mais recente de suspensão de exigibilidade, também não interrompe a prescrição, razão pela qual é mais sábio a Fazenda concedê-lo no curso do processo judicial, quando a prescrição tiver sido interrompida.

Convém lembrar que as causas de suspensão ou exclusão do crédito tributário não comportam interpretação analógica nos termos do art. 111 do Código Tributário Nacional, assim o intérprete não pode estender a aplicação de tais normas. ${ }^{10}$

9 Nesse sentido: MARTINS, Ives Gandra. A prescrição no direito tributário brasileiro. São Paulo: Resenha Tributária, 1977, p. 356. BALEEIRO, Aliomar. Suspensão da exigibilidade do crédito tributário e prescrição. Revista de Direito Tributário, n. 9/10, [s.d.] pág. 9. HARADA, Direito..., p. 466. Contra, entendendo que são causas de suspensão da prescrição: CALCIOLARI, Ricardo Pires; CORDIOLI, Maximilian Hagl. A prescrição intercorrente em matéria tributária. Direito Tributário Atual, n. 18, [s.d.], p. 371-372. Esses últimos autores, brilhantes, principalmente por serem graduandos, argumentam com base na prescrição como sendo perda do direito de ação, inexecutável pela suspensão da exigibilidade do crédito tributário, contudo tal não nos parece correto, pois como dissemos no texto, no caso do Direito Tributário há a perda do próprio crédito e não da pretensão ou da ação. 10 Conforme BALEEIRO, op.cit., p. 9. 
O prazo de prescrição pode ser interrompido, quando começa do zero novamente, $\mathrm{e}$ isso nas seguintes situações previstas no parágrafo único do art. 174, na sua redação original:

1. pela citação pessoal feita ao devedor;

2. pelo protesto judicial;

3 . por qualquer ato judicial que constitua em mora o devedor;

4. por qualquer ato inequívoco ainda que extrajudicial, que importe em reconhecimento do débito pelo devedor.

Convém lembrar que, nos termos do art. 125, III, do Código Tributário Nacional, salvo disposição de lei em contrário, no caso de solidariedade a interrupção da prescrição, em favor ou contra um dos obrigados, favorece ou prejudica aos demais.

A consulta nãoé motivo de interrupção ou suspensão do prazo prescricional."

Esse parágrafo único do art. 174 foi alterado, na sua primeira hipótese, pela Lei Complementar 118 de nove de fevereiro de 2005 que dispôs que tal interrupção ocorre "pelo despacho do juiz que ordenar a citação em execução fiscal", tendo tal regra entrado em vigor no dia 09 de junho de 2005.

A regra da Lei Complementar 118 é de natureza processual ou material?
Se for de natureza processual, ela se aplica aos feitos em curso desde logo, caso contrário não.

A prescrição é questão de direito material, pois ela ocorre normalmente fora do processo, não existindo direito processual fora do processo. ${ }^{12}$

Assim, a Lei Complementar 118, tratando de norma material nesse caso, só se aplica aos fatos geradores posteriores a ela e não desde logo, como ocorreria com uma norma de natureza processual.

Entretanto, essa regra não é nova, pois já prevista no art. Art. $8^{\circ}, \S 2^{\circ}$, da Lei $6.830 / 80$, cuja validade nesse ponto passamos a questionar.

\section{A PRESCRIÇÃO TRIBUTÁRIA E A LEI $\mathbf{6 . 8 3 0 / 8 0}$}

Na execução fiscal se cobra dívidas de natureza tributária e dívidas de natureza não tributária como, por exemplo, a multa de trânsito. ${ }^{13}$

Com relação à dívida de natureza não tributária as regras sobre prescrição da Lei 6.830/80 são plenamente válidas. A dúvida surge no que diz respeito às dívidas de natureza tributária.

A respeito da prescrição, dispõe a Constituição de 1988:

11 Conforme CASSONE; CASSONE, Processo..., p. 47.

12 Contra, entendendo que prescrição é questão de direito formal: ICHIHARA, Direito..., p. 170. Esse autor não fornece argumentos para embasar sua posição.

13 Nesse sentido: CAIS, Oprocesso..., p. 692. 
Art. 146. Cabe à lei complementar: [...]

III - estabelecer normas gerais em matéria de legislação tributária, especialmente sobre: [...]

b) obrigação, lançamento, crédito, prescrição e decadência tributários; [...] (Grifo nosso).

Assim, prescrição tributária é matéria reservada à lei complementar e, por isso, a partir da Constituição de 1988 , não pode ser tratada pela lei ordinária.

Dessa forma, a Lei 11.051/2004, que tratou da prescrição intercorrente, alterando a Lei 6.830 , é inconstitucional por não ser lei complementar. ${ }^{14}$

Contudo, a Constituição anterior, não mencionava expressamente a prescrição tributária como sendo reserva de lei complementar, da forma como hoje ocorre:

Art. $18 \S 1^{\circ}$ Lei complementar estabelecerá normas gerais de direito tributário, disporá sobre os conflitos de competência nesta matéria entre a União, os Estados, o Distrito Federal e os Municipios, e regulará as limitações constitucionais do poder de tributar: (Grifo nosso).

O que seria matéria de normas gerais de Direito Tributário sempre foi muito controvertido, tendo a doutrina gasto rios de tinta e toneladas de papel para tratar do assunto, mas sem sucesso, o que fez o Constituinte de 1988 ser mais específico quando tratou do tema.

Caso a prescrição seja entendida como sendo matéria de norma geral as disposições da Lei $6.830 / 80$ a esse respeito seriam inconstitucionais desde o início, pois essa é uma lei ordinária.

Se for adotado o entendimento contrário, a Lei $6.830 / 80$ não seria inconstitucional na sua origem e a parte dela que trata de prescrição teria se tornado lei complementar pelo fenômeno da recepção, tal como ocorreu com o Código Tributário Nacional, inicialmente lei ordinária, e convertido para lei complementar pela Constituição de 1967.

O Legislador tem um poder que foi constituído pelo Poder Constituinte e somente esse Poder Constituinte pode impor limites ao Legislador, não sendo lícito ao intérprete criar outros.

No caso, como o Poder Constituinte da Constituição anterior não disse o que era norma geral, cabia ao Legislador fazêlo, assim o Legislador tinha liberdade para tratar da prescrição, não expressamente prevista pelo Poder Constituinte como reserva de lei complementar.

Além disso, a autonomia dos estados e municípios, consagrada pela Constituição anterior, também exige essa interpretação, tolhendo a União de poder não expressamente outorgado a ela pelo Po-

14 Lei $6.830 / 80$, art. $40, \S 4$ Se da decisão que ordenar o arquivamento tiver decorrido o prazo prescricional, o juiz, depois de ouvida a Fazenda Pública, poderá, de ofício, reconhecer a prescrição intercorrente e decretá-la de imediato. (Incluído pela Lei n ${ }^{\circ} 11.051$, de 2004). 
der Constituinte de interferir no âmbito dos estados e municípios.

Em virtude dessa liberdade é que se pode afirmar que o legislador federal, estadual ou municipal poderia tratar de prescrição tributária na lei ordinária, antes de 1988, o que foi feito na Lei $6.830 / 80$ pelo legislador federal.

Poderia ser discutido se as normas sobre prescrição da Lei $6.830 / 80$ se aplicariam apenas aos tributos da União, contudo, embora algumas vozes tenham se levantado nesse sentido, ${ }^{15}$ deve-se aceitar a aplicação das regras federais às demais entidades da Federação, mesmo antes da Constituição de 1988 devido à natureza concentradora de nossa Federação, fruto de sua própria origem. ${ }^{16}$

Mas, com o advento da Constituição de 1988, as normas sobre prescrição previstas na Lei $6.830 / 80$ passaram a ser lei complementar, pelo fenômeno da recepção supra mencionado, aplicandose a todas as entidades da Federação. ${ }^{17}$

Nessa linha de raciocínio é válida e lei complementar a regra prevista no art. $2^{\circ}$. da Lei $6.830 / 80$ que diz:

Art. $2^{\circ}$ - Constitui divida ativa da Fazenda Pública aquela definida como tributária ou não tributária na Lei $n^{\circ} 4.320$, de 17 de março de 1964 , com as alterações posteriores, que estatui normas gerais de direito financeiro para elaboração e controle dos orçamentos e balanços da União, dos estados, dos municípios e do Distrito Federal. [...]

$\S 3^{\circ}$ - A inscrição, que se constitui no ato de controle administrativo da legalidade, será feita pelo órgão competente para apurar a liquidez e certeza do crédito e suspenderá a prescrição, para todos os efeitos de direito, por 180

15 Contra a aplicação das normas do Código Tributário Nacional sobre prescrição e decadência aos Estados e Municípios vide ATALIBA, Geraldo. Normas gerais de direito financeiro e tributário e autonomia dos estados e municípios. Revista de Direito Público, n. 10, [s.d.]. em especial p. 79. BORGES, Souto Maior. Normas gerais de direito tributário. Revista de Direito Público, n. 31, [s.d.] em especial p. 259; CARVALHO, Paulo de Barros. Curso de direito tributário. 14. ed. São Paulo: Saraiva, 2002, p. 207.

16 Nesse sentido ARZUA, Heron. Contribuição ao estudo dos tributos parafiscais. São Paulo: Resenha Tributária, IBET, 1974, p. 42; COÊLHO, Sacha Calmon Navarro. Comentários à Constituição de 1988. Rio de Janeiro: Forense, 1990, p. 133. TORRES, Heleno Taveira. Funções das Leis Complementares no Sistema Tributário Nacional Hierarquia das Normas - Papel do Código Tributário Nacional no Ordenamento. Revista de Direito Tributário, n. 84, [s.d.], p. 54-55. CALCIOLARI; CORDIOLI, A prescrição..., p. 366-367. Embora com fundamento diverso do texto por entender que prescrição não é questão de direito material: THEODORO JÚNIOR, Humberto. Comentários à Lei de Execução Fiscal. Rio de Janeiro: Forense, 1981, p. 194.

17 Nesse sentido: CALCIOLARI; CORDIOLI, A prescrição..., p. 368-369. Contra, entendendo que não houve recepção: CAIS, O processo..., p. 691. 
dias, ou até a distribuição da execução fiscal, se esta ocorrer antes de findo aquele prazo. $[\ldots]^{18}$

Também é válida a regra do art. $8^{\circ}$. da mesma lei:

Art. $8^{\circ}$. [...] $\S 2^{\circ}-$ O despacho do juiz, que ordenar a citação, interrompe a prescrição.

Essa norma revogou o disposto no art. 174, parágrafo único, I, do Código Tributário Nacional tendo em vista a regra que diz: lex posteriori derogat priori.

Da mesma forma é o que ocorre com o caput do art. 40 da citada lei:

Art. 40 - O juiz suspenderá o curso da execução, enquanto não for localizado o devedor ou encontrados bens sobre os quais possa recair a penhora, $e$, nesses casos, não correrá o prazo de prescrição.

Esse dispositivo deve ser harmonizado com o art. 174 do Código Tributário Nacional que no seu parágrafo único diz que a prescrição é interrompida pela citação pessoal feita ao devedor, ou seja, somente se o devedor não for localizado e nem seus bens, haverá a suspensão da prescrição que recomeça a correr de onde parou tão logo seja encontrado o devedor ou bens passíveis de penhora.

Mesmo se a falta de andamento for imputável ao serviço judiciário ou ao fisco haverá a prescrição, pois tal fato não é previsto na lei como caso de suspensão ou interrupção da prescrição. ${ }^{19}$

Isso parece contrariar a Súmula 106 do STJ que diz:

Proposta a ação no prazo fixado para o seu exercício, a demora na citação, por motivos inerentes ao mecanismo da Justiça, não justifica o acolhimento da argüição de prescrição ou decadência.

Ocorre que, no que tange aos tributos, a simples propositura de ação não interrompe e nem suspende a prescrição.

Dessa forma, se a citação ou a penhora não ocorrer por desleixo do fisco a prescrição continuará correndo naqueles casos de fato geradores anteriores à Lei Complementar 118, como mencionado supra, ou seja, haveria prescrição intercorrente, a qual passamos a tratar em seguida.

\section{A PRESCRIÇÃO INTERCORRENTE}

Denomina-se intercorrente a prescrição ocorrida no curso do feito e tal

18 Regra semelhante encontra-se no Decreto-lei 1.793/80 que, pelas razões expostas no texto, aplica-se a todas as entidades da Federação, diversamente do que ensina HARADA, Direito financeiro..., p. 467, nota 45.

19 Contra: CASSONE; CASSONE, Processo..., p. 47. 
instituto é aceito pelo STF como válido em nosso Direito em alguns casos. ${ }^{20}$

Não há falar-se em prescrição intercorrente durante o processo administrativo, pois ela ainda não começou a correr, podendo ocorrer a decadência. ${ }^{21}$

O STJ, por sua vez, proclama a existência da prescrição intercorrente tributária na execução fiscal na súmula 314 :

Em execução fiscal, não localizados bens penhoráveis, suspende-se o processo por um ano, findo o qual se inicia o prazo da prescrição qüinqüenal intercorrente.

Essa súmula traz como referência legislativa o art. 174 do Código Tributário Nacional e o art. 40 da Lei $6.830 /$ 80 , baseando-se em precedentes que se iniciaram em 1998.22

Diz o art. 40:
Art. 40 - O juiz suspenderá o curso da execução, enquanto não for localizado o devedor ou encontrados bens sobre os quais possa recair a penhora, e, nesses casos, não correrá o prazo de prescrição. (Grifo nosso).

Esse. ${ }^{23}$ Com efeito, ele diz que a prescrição se suspende enquanto não for localizado o devedor ou encontrados bens, assim, a contrário senso, fora desses casos, ocorreria a prescrição intercorrente por simples negligência da $\mathrm{Fa}$ zenda em casos em que houvessem bens ou fosse encontrado o devedor, pois aí não haveria suspensão da prescrição que, assim, continuaria a correr e seria intercorrente porque ocorreria durante a execução. ${ }^{24}$

Não sendo encontrados bens ou o devedor o feito será encaminhado ao arquivo, mas aí não haverá prescrição,

20 Súmula 264: "Verifica-se a prescrição intercorrente pela paralisação da ação rescisória por mais de cinco anos."

Súmula 327: "O direito trabalhista admite a prescrição intercorrente."

21 Contra: COSTA, Alcides Jorge. Decadência, prescrição e prescrição intercorrente em matéria tributária. Cadernos de Direito Tributário e Finanças Públicas, v. 5, n. 21, out./ dez. 1997. A favor, mas com outros fundamentos: CALCIOLARI; CORDIOLI, $A$ prescrição..., p. 374.

22 Primeira Seção, julgado em 12.12.2005, DJ 08.02.2006 p. 258. http:/www.stj.gov.br/ $\mathrm{SCON} /$ sumulas/toc.jsp?tipo_visualizacao $=\&$ livre $=\% 40$ docn $\& \& b=\mathrm{SUMU} \& \mathrm{p}=$ true $\& \mathrm{t}=\& \mathrm{l}=10 \& \mathrm{i}=11$. Site visitado no dia 28 de agosto de 2006 .

23 Contra, entendendo que a prescrição intercorrente é prevista no parágrafo único do art. 174 do Código Tributário Nacional: CAIS, O processo..., p. 694. Mantemos a posição do texto porque nada há no parágrafo único do art. 174 do Código Tributário Nacional que faça menção à prescrição intercorrente.

24 No sentido de que a inércia do fisco na execução fiscal geraria a prescrição intercorrente: ICHIHARA, Direito..., p. 169. Contra, entendendo que a prescrição intercorrente continua a correr no arquivo, mesmo não encontrados bens ou o devedor: CAIS, op. cit., p. 691 . Contudo, mantemos a posição do texto, pois de acoido com a redação legal. 
pois ela estará suspensa, ${ }^{25}$ prosseguindo a execução a qualquer momento em que o fisco encontrar o devedor ou bens passíveis de penhora. ${ }^{26}$

Conforme visto acima, ocorreria a denominada prescrição intercorrente no caso de não citação ou não penhora por falta reputável ao fisco, ${ }^{27}$ não tendo amparo legal, data venia, o prazo de um ano previsto na súmula. A Lei 6.830 / 80 , no seu art. $40, \S 2^{\circ},{ }^{28}$ fala no prazo de um ano, mas não com relação a eventual recomeço da prescrição.

Convém lembrar que a súmula, no que carece de amparo legal, não é válida, pois a Constituição, como dissemos, exige lei complementar para tratar de prescrição, o mesmo fazendo o Código Tributário Nacional no seu art. 97 que exige respeito ao princípio da estrita legalidade tributária, sendo a súmula, nesse ponto, ilegal e inconstitucional. ${ }^{29}$
Contudo, tal levaria cinco anos para acontecer, assim, seria muito melhor o juiz aplicar o disposto no art. 267, III, combinado com o parágrafo primeiro do mesmo artigo, todos do CPC, conforme autorizado pelo art. $1^{\circ}$. da Lei 6.830:

Art. 267. Extingue-se o processo, sem iulgamento do mérito: [...]

III - quando, por não promover os atos e diligências que the competir, o autor abandonar a causa por mais de 30 (trinta) dias; [..]

$\S 1^{\circ}$ O juiz ordenará, nos casos dos ns. II e III, o arquivamento dos autos, declarando a extinção do processo, se a parte, intimada pessoalmente, não suprir a falta em 48 (quarenta e oito) horas. [...]

Convém ressaltar que simples pedido de prosseguimento não dá andamento ao feito e a penalidade supra mencionada só não deve ser aplicada se realmente a Fazenda der andamento ao feito.

25 Contra, entendendo que há interrupção da prescrição: THEODORO JÚNIOR, Lei de execução..., p. 51; e FLAKS, Milton. Comentários à Lei de Execução Fiscal. Rio de Janeiro: Forense, 1981, p. 194. Mantemos o entendimento do texto, pois o art. 40 fala claramente em suspensão, não tendo amparo legal interpretação diversa.

26 Lei 6.830: art. $40 \S 1^{\circ}$ - Suspenso o curso da execução, será aberta vista dos autos ao representante judicial da Fazenda Pública. [...] $§ 2^{\circ}$ - Decorrido o prazo máximo de 1 (um) ano, sem que seja localizado o devedor ou encontrados bens penhoráveis, o juiz ordenará o arquivamento dos autos. $\S 3^{\circ}$ - Encontrados que sejam, a qualquer tempo, o devedor ou os bens, serão desarquivados os autos para prosseguimento da execução.

27 Contra entendendo que no caso de negligência do fisco caberia apenas a extinção do feito ou a perempção: CALCIOLARI; CORDIOLI, A prescrição..., p. 374-375.

$28 \S 2^{\circ}$ - Decorrido o prazo máximo de 1 (um) ano, sem que seja localizado o devedor ou encontrados bens penhoráveis, o juiz ordenará o arquivamento dos autos.

29 Art. 97. Somente a lei pode estabelecer: I - a instituição de tributos, ou a sua extinção; [...] VI - as hipóteses de exclusão, suspensão e extinção de créditos tributários, ou de dispensa ou redução de penalidades. (grifo nosso) 


\section{CONCLUSÕES}

Do exposto podemos concluir o seguinte:

1. Com a prescrição tributária ocorre a extinção do crédito tributário e não meramente a extinção da ação ou da pretensão;

2. O pagamento de uma dívida prescrita tributária não é válido e pode ser repetido;

3. A prescrição tributária diverge da decadência tributária por ser essa a perda do direito de constituir o crédito tributário pelo lançamento;

4. Constituído o crédito tributário, o que, na linguagem do Código Tributário Nacional, significa tornar o crédito exeqüível pela determinação de sua liquidação e certeza, começa a correr o prazo de prescrição;

5. A constituição do crédito tributário ocorre com o lançamento, naqueles casos em que o ato da autoridade é imprescindível, ou seja, no denominado lançamento de ofício;

6. Nos casos em que o lançamento se dá por um auto de infração, começa daí a correr o prazo prescricional;

7. No caso de lançamento por homologação e no de declaração de dívida feita pelo contribuinte, dependendo de uma averiguação pelo fisco, se houver uma diferença em favor do fisco, o prazo será de decadência;

8. A prescrição do crédito tributário ocorre em cinco anos, contados da data da sua constituição definitiva, ou seja, do término do lançamento definitivo;

9. O lançamento só é mesmo definitivo quando insuscetível de recurso ou de revisão de ofício, de acordo com as leis de cada entidade tributante;

10. O Código Tributário Nacional não trata especificamente da suspensão da prescrição;

11. Não se pode dizer que a suspensão da exigibilidade, ou seja, da pretensão, seja causa de suspensão da prescrição tributária:

12. O Código é taxativo ao prever a suspensão da prescrição apenas no art. 155, parágrafo único, ou seja, nas moratórias, e somente naquelas em que houver dolo ou simulação do beneficiado, ou de terceiro em benefício daquele;

13. O prazo de prescrição pode ser interrompido nos casos do art. 174, parágrafo único, do Código Tributário Nacional: pela citação pessoal feita ao devedor; pelo protesto judicial; por qualquer ato judicial que constitua em mora o devedor; ou por qualquer ato inequívoco ainda que extrajudicial, que importe em reconhecimento do débito pelo devedor;

14. Salvo disposição de lei em contrário, no caso de solidariedade a interrupção da prescrição, em favor ou contra um dos obrigados, favorece ou prejudica aos demais;

15. A consulta não é motivo de interrupção ou suspensão do prazo prescricional;

16. A primeira hipótese do parágrafo único do art. 174 foi alterada pela Lei Complementar 118 de 09 de fevereiro de 2005, ocorrendo a interrupção pelo despacho do juiz que ordenar a citação em execução fiscal, tendo tal regra entrado em vigor no dia 
09 de junho de 2005, sendo essa uma norma de direito material, como o são as normas relacionadas à prescrição;

17. Com relação à dívida de natureza não tributária as regras sobre prescrição da Lei $6.830 / 80$ são plenamente válidas;

18. Prescrição tributária é matéria reservada à lei complementar a partir da Constituição de 1988;

19. A Lei $11.051 / 2004$, que tratou da prescrição intercorrente, alterando a Lei 6.830 , é inconstitucional por não ser lei complementar;

20. O legislador federal, estadual ou municipal poderia tratar de prescrição tributária na lei ordinária, antes de 1988, o que foi feito na Lei $6.830 / 80$ pelo legislador federal, devendo-se aceitar a aplicação das regras federais às demais entidades da Federação, mesmo antes da Constituição de 1988 devido à natureza concentradora de nossa Federação;

21. Com o advento da Constituição de 1988 , as normas sobre prescrição previstas na Lei $6.830 / 80$ passaram a ser lei complementar, pelo fenômeno da recepção, aplicando-se a todas as entidades da Federação;

22. A regra do art. $2^{\circ}, \S 3^{\circ}$, da Lei $6.830 / 80$ que diz que a inscrição na dívida ativa suspenderá a prescrição, para todos os efeitos de direito, por 180 dias, ou até a distribuição da execução fiscal, se esta ocorrer antes de findo aquele prazo, é válida e lei complementar;

23. A regra do art. $8^{\circ}, \S 2^{\circ}$, da Lei $6.830 / 80$ pela qual o despacho do juiz, que ordenar a citação, interrompe a prescrição, é válida, lei complementar e revogou o disposto no art. 174, parágrafo único, l, do Código Tributário Nacional;

24. A regra da suspensão da prescrição do art. 40 da Lei $6.830 / 80$ é válida e lei complementar, mas somente haverá a suspensão da prescrição se o devedor não for localizado e nem seus bens, e ela recomeça a correr de onde parou tão logo seja encontrado o devedor ou bens passíveis de penhora;

25. Mesmo se a falta de andamento for imputável ao serviço judiciário ou ao fisco haverá a prescrição, pois tal fato não é previsto na lei como caso de suspensão ou interrupção da prescrição;

26. no que tange aos tributos, a simples propositura de ação não interrompe e nem suspende a prescrição;

27. Não há falar-se em prescrição intercorrente durante o processo administrativo, pois ela ainda não começou a correr, podendo ocorrer a decadência;

28. O art. 40 da Lei $6.830 / 80$ prevê a prescrição intercorrente no caso em que, localizado o devedor ou encontrados bens, haja negligência da Fazenda em dar andamento à execução;

29. Não tendo amparo legal e não é válido o prazo de um ano previsto na súmula 314 do $\mathrm{STJ}$;

30. $O$ art. $40, \S 2^{\circ}$, da Lei $6.830 / 80$ fala no prazo de um ano, mas não com relação a eventual recomeço da prescrição; e

31. O juiz pode aplicar na execução fiscal o art. 267 , III, c. c. o $\S 1^{\circ}$, do mesmo artigo, do Código de Processo Civil c. c. o art. $1^{\circ}$. da Lei $6.830 / 80$, sendo que o simples pedido de prosseguimento não dá andamento ao feito. 


\section{REFERÊNCIAS}

ARZUA, Heron. Contribuição ao estudo dos tributos parafiscais. São Paulo: Resenha Tributária, IBET, 1974.

ATALIBA, Geraldo. Normas gerais de direito financeiro e tributário e autonomia dos estados e municípios. Revista de Direito Público, n. 10, [s.d.].

BALEEIRO, Aliomar. Suspensão da exigibilidade do crédito tributário e prescrição. Revista de Direito. Tributário, n. 9/10, [s.d.]

BORGES, Souto Maior. Normas gerais de direito tributário. Revista de Direito Público, n. 31, [s.d.]

CAIS, Cleide Previtalli. O processo tributário. 4. ed. São Paulo: Revista dos Tribunais, 2004.

CALCIOLARI, Ricardo Pires; CORDIOLI, Maximilian Hagl. A prescrição intercorrente em matéria tributária. Direito Tributário Atual, n. 18, [s.d.]

CARVALHO, Paulo de Barros. Curso de direito tributário. 14. ed. São Paulo: Saraiva, 2002.

CASSONE, Vittorio; CASSONE, Maria Eugenia Teixeira. Processo tributário. 4. ed. São Paulo: Atlas, 2003.

COÊLHO, Sacha Calmon Navarro. Comentários à Constituição de 1988. Rio de Janeiro: Forense, 1990.
. Curso de direito tributário brasileiro. 6. ed. Rio de Janeiro: Forense, 2001.

. Manual de direito tributário. 2. ed. Rio de Janeiro: Forense, 2003.

COSTA, Alcides Jorge. Decadência, prescrição e prescrição intercorrente em matéria tributária. Cadernos de Direito Tributário e Finanças Públicas, v. 5, n. 21, out./dez. 1997.

FLAKS, Milton. Comentários à Lei de Execução Fiscal. Rio de Janeiro: Forense, 1981.

HARADA, Kiyoshi. Direito financeiro e tributário. 11. ed. São Paulo: Atlas, 2003.

ICHIHARA, Yoshiaki. Direito tributário. 9. ed. São Paulo: Atlas, 2000.

MARTINS, Ives Gandra. A prescrição no direito tributário brasileiro. São Paulo: Resenha Tributária, 1977.

THEODORO JÚNIOR, Humberto. Comentários à Lei de Execução Fiscal. Rio de Janeiro: Forense, 1981.

TORRES, Heleno Taveira. Funções das Leis Complementares no Sistema Tributário Nacional - Hierarquia das Normas - Papel do Código Tributário Nacional no Ordenamento. Revista de Direito Tributário, n. 84, [s.d.] 
